Southampton, Liverpool, Lewisham, and Marylebone. ${ }^{5}$ The National Association of Health Authorities and Trusts has agreed that some form of exchange of information for providers and commissioners is desirable, and this process is currently being developed.

West Yorkshire Health Authority has already committed itself to developing a range of complementary therapies based in primary care. ${ }^{5}$ This experimental approach needs to continue if commissioners are to think laterally about health care while struggling with all their other priorities. The planned enhancement of commissioning based in primary care will almost certainly increase the opportunities for complementary medicine as a real alternative to some secondary care services-for example, for the management of stress and chronic back pain. The challenge for commissioners is to substitute complementary medicine for conventional treatments rather than simply add to the range of treatments and costs.
Complementary medicine in its broadest sense also needs to try to explain why it works. The lack of such explanations are a major concern for most conventionally trained doctors, who struggle with concepts such as the power of the placebo effect and the role of Avogadro's number and homoeopathic dilutions. That may be hard; in the meantime, the immediate issue for research in complementary medicine is not why things work but to show that they do.

IAIN SMITH

Nuffield Institute for Health,

Senior lecturer in health services research Leeds LS2 9PL

1 Cameron-Blackie G, Mouncer Y. Complementary therapies in the NHS. Birmingham: National Association of Health Authorities and Trusts, 1993. (Research paper 10.)

2 BMA Complementary medicine: new approaches to good practice. London: BMA, 1993.

3 Sheldon TA. Please bypass the PORT. BMF 1994;309:142-3.

4 Black N. Experimental and observational methods of evaluation. BMF 1994;309:541

5 Worth C. Added value? Complementary therapies in the NHS. Huddersfield: West Yorkshire Health Authority, 1994.

\title{
Tackling inequalities in health
}

\section{Great need for evidence based interventions}

What can be done about socioeconomic inequalities in health? A report by the King's Fund contains an impressive agenda for action." The objective of the report was "to outline a number of practical and affordable ways in which the situation could be substantially improved, if the political will existed to recognise that tackling inequalities in health is a fundamental requirement of social justice for all citizens."

The report identifies four areas for intervention: the physical environment, social and economic factors, barriers to adopting a healthier personal lifestyle, and access to appropriate and effective health and social services. For each area one factor has been selected to illustrate possible policy initiatives: housing, income maintenance, smoking, and access to health care. The initiatives range from the development of innovative health education programmes to investments in social housing (to be financed by, among other things, the abolition of tax relief on mortgages) and from ensuring an equitable allocation of NHS resources to changes in the tax system (for example, an increase in the highest rate of income tax).

This brief summary of the report cannot do justice to the richness of its ideas. This richness makes the report a welcome complement to a lucid but much thinner discussion paper by the World Health Organisation that was published a few years ago. ${ }^{2}$ It also reinforces a recent paper on inequalities in health issued by the BMA, which concluded that "a total rather than service-orientated approach is needed across all sectors of government." The BMA's paper identified a wider range of policy areas that should be involved in this strategy: economic policy ("particularly taxation policy"), provision of welfare benefits, education and child care, unemployment, environment, housing, transport, and leisure. ${ }^{3}$

The broad and varied approach advocated in these reports certainly fits the scale and nature of the problem: inequalities in health are a widespread phenomenon, resulting from a complex interplay of many different factors; substantial reductions in them are unlikely unless some of their root causes, such as inequality of income, are addressed. On the other hand, the wide range of policy options also shows uncertainty about which measures are necessary and likely to be effective. Much more helpful would be a more parsimonious package that targeted several specified key areas of concern within the larger domain of socioeconomic inequalities in health, focused on the known causes of these inequalities, and used interventions of established efficacy in reducing these inequalities. Unfortunately, current knowledge allows only the first two of these requirements to be (partially) met.

This can be shown for one key area of concern: the widening of the difference in mortality between rich and poor people. Over the past three or four decades there has been consistent evidence of increasing socioeconomic inequalities in mortality, both in Britain and in several other industrialised countries. $^{4-9}$ There are two competing explanations. One emphasises the possible role of increasing inequalities in income and one focuses on the possible contribution of changes in the distribution of behavioural risk factors. For Britain, evidence exists that the increases in the size of socioeconomic inequalities in mortality are related to increases in the size of inequalities in income, ${ }^{1011}$ and this relation also emerges from international comparisons at one point in time. ${ }^{12}$ The competing explanation for the widening difference in mortality focuses on changes in the social distribution of behavioural risk factors. One of the main contributors to the widening difference in mortality is ischaemic heart disease, which over the past 40 years has changed from being an upper class to a lower class disease. These changes are mirrored by comparable changes in risk factors for ischaemic heart disease, such as smoking and obesity. ${ }^{13}$

Evidence thus suggests that both reducing inequalities in income and reducing the social gradient in smoking and other behavioural risk factors could result in a slowing down or perhaps even reversal of the widening difference in mortality. Unfortunately, however, this is not enough. Both types of intervention have a price, in political, economic, or simply monetary terms. To justify the costs and to enable policymakers to choose rationally from the available policy options, quantitative information is needed on the effectiveness of these interventions. Public health researchers and practitioners frequently criticise those practising clinical medicine for the lack of evidence of the effectiveness of medical interventions. ${ }^{14}$ They argue, legitimately, that knowledge of the aetiology and pathophysiology of a disease is not enough to justify treatments that seemingly address these factors. What 
is also needed is evidence of the effectiveness of medical interventions, preferably collected in carefully controlled experiments. The same "evidence based" rigour should be striven for in public health.

Scientifically valid evidence of the effectiveness of the type of interventions advocated by the reports mentioned above is extremely scarce. ${ }^{15}$ Randomised controlled trials will usually be impossible, but other powerful research designs are available, ${ }^{16}{ }^{17}$ and advantage should also be taken of the results of "natural" experiments, in which favourable changes occur for reasons other than to reduce inequalities in health (for example, changes in employment opportunities, housing, or prices of cigarettes). Whenever possible, effects should be expressed in terms of changes in the size of socioeconomic inequalities in health; various such measures are available. ${ }^{18}$

Political will should be mobilised, not only to implement some of the recommendations of the King's Fund's and similar reports but also to sponsor the research necessary to evaluate the effects. After researchers have documented the existence of inequalities in health and have studied the explanation of inequalities in health there is one further contribution that they can make to health policy: studying the effectiveness of interventions aimed at reducing inequalities in health. This is a substantial undertaking, for which international cooperation is likely to be required: no single country can provide all the "natural" and induced variation that is necessary to evaluate the relevant policy options.

In the Netherlands a government sponsored five year programme aimed at evaluating several possible interventions to reduce inequalities in health is already under way ${ }^{19}$; the World Health Organisation's discussion paper contains other examples of national, regional, and local initiatives. ${ }^{2}$ Attempts at reducing inequalities in health cannot be but illustrations of Rudolf Virchow's famous dictum "Medicine is a social science and politics nothing but medicine on a grand scale." ${ }^{20}$ Let's try to make this a rational form of medicine.

JOHAN P MACKENBACH Professor

Department of Public Health,

Erasmus University,

Rotterdam,

Netherlands

1 Benzeval $M$, Judge $\mathrm{K}$, Whitehead $\mathrm{M}$, eds. Tackling inequalities in health; an agenda for action. London: King's Fund, 1995.

2 Dahlgren G, Whitehead M. Policies and strategies to promote equity in health. Copenhgen: World Health Organisation, 1992.

3 BMA Board of Science and Education. Inequalities in health. London: BMA, 1995.

4 Townsend P, Davidson N, Whitehead M, eds. Inequalities in health (the Black report and the health divide). London: Penguin, 1988.

5 Marmot MG, McDowall ME. Mortality decline and widening social inequalities. Lancet 1986;ii:274-6.

6 Phillimore P, Beattie A, Townsend P. Widening inequality in northern England, 1981-9. BMf 1994;308:1125-8.

7 Desplanques G. L'inégalité devant la mort. Economie et Statistique 1984;14:29-50.

8 Valkonen T, Martelin T. Rimpela A, Notkola V, Savela S. Socio-economic mortality differences in Finland 1981-90. Helsinki: Statistics Finland, 1993.

9 Pappas G, Queen S, Hadden W, Fisher G. The increasing disparity in mortality between socioeconomic groups in the United States, 1960 and 1986. N Engl f Med 1993;329:103-9.

10 Wilkinson RG. Class mortality differentials, income distribution and trends in poverty 1921-1981. fournal of Social Policy 1989;18:307-35.

11 Wilkinson RG. Income distribution and mortality: a "natural" experiment. Sociology of Health and Illness 1990;12:391-412.

12 Kunst AE, Mackenbach JP. The size of mortality differences associated with educational level in nine industrialised countries. Am $\mathcal{f}$ Public Health 1994;84:932-7.

13 Rose G, Marmot MG. Social class and coronary heart disease. Br Heart f 1981;45:13-9.

14 Cochrane A. Effectiveness and efficiency: random reflections on health services. London: Nuffield Provincial Hospitals Trust, 1972.

15 Gepkens A, Gunning-Schepers LJ. Interventies ter vermindering van sociaal-economische gezondheidsverschillen. Een evaluatie van reeds uitgevoerde Nederlandse en buitenlandse interventies ter vermindering van sociaal-economische gezondheidsverschillen. Amsterdam: Institute for Social Medicine, University of Amsterdam, 1993.

16 Koepsell TD, Wagner EH, Cheadle AC, Patrick DL, Martin DC, Diehr PH, et al. Selected methodological issues in evaluating community-based health promotion and disease prevention programmes. Annu Rev Public Health 1992;13:31-57.

17 Campbell DT, Stanley JC. Experimental and quasi-experimental design for research. Chicago: American Educational Research Association, 1966.

18 Kunst AE, Mackenbach JP. Measuring socioeconomic inequalities in health. Copenhagen: World Health Organisation, 1994.

19 Mackenbach JP. Socioeconomic inequalities in health in the Netherlands: impact of a five year research programme. $B M F$ 1994;309:1487-91.

20 Rosen G. What is social medicine? In: Rosen G, ed. From medical police to social medicine; essays on the history of health care. New York: Science History Publications, 1974:62.

\section{Amblyopia: could we do better?}

\section{Doctors need to pay as much attention to treatment and compliance as to detection}

Amblyopia is a common cause of visual loss affecting between 1 and $4 \%$ of the population. ${ }^{1}$ In most cases it is unilateral and is associated with either misalignment of the eyes (strabismus) or a difference in refraction between the two eyes (anisometropia). Treatment, which is effective only in childhood, consists of prescribing glasses when appropriate and occluding the good eye to force the child to use the amblyopic eye. There is no doubt that this treatment can be highly effective, and a recent prospective study reported cure-that is, visual acuity within one line of that in the unaffected eye-in $89 \%$ of patients. ${ }^{2}$ Despite this, amblyopia remains widely prevalent in adults. Why is this? How important a problem is it? And, what, if anything, needs to be done?

Most people with amblyopia are barely aware of their disability since they rely on their good eye. Certainly their visual loss does not seem to interfere with academic performance. However, visually demanding tasks for which perception of distance is important are much more difficult, and people who suffer from amblyopia are excluded from many positions in the armed forces, and in fire and police services and the transport industries.

Of even more concern than this loss of vision in one eye is the devastating disability suffered by people with amblyopia if they lose vision in their good eye. Few epidemiological data exist on the frequency of this. Nevertheless, a retrospective study in Finland concluded that patients with amblyopia are at greatly increased risk of blindness, ${ }^{3}$ and $11 \cdot 8 \%$ of blind eyes in the population based Framingham study were blind from amblyopia alone. ${ }^{4}$ Taylor's calculation of 2000 people blinded in the United Kingdom by amblyopia and subsequent loss of the good eye ${ }^{5}$ may underestimate the visual morbidity since most patients will have significant visual impairment that does not meet the criteria for registration as blind. In addition, patients with amblyopia who develop cataract may have surgery delayed because of fear of the risk of surgery to their only good eye.

Ophthalmologists and orthoptists believe that the earlier that treatment for amblyopia is started the better the results. This view is based on the demonstration of a sensitive period in animal models of amblyopia beyond which amblyopia cannot be treated and on the observation that the speed of response to amblyopia treatment is inversely proportional to the age of the child: beyond the age of about 7 children respond poorly to treatment. Thus there has been great enthusiasm for early detection by vision screening programmes; Stewart-Brown et al found that $94 \%$ of health authorities in England and Wales were doing preschool vision screening. ${ }^{6}$ Unfortunately, although the effectiveness of different screening programmes at detecting amblyopia has been investigated, ${ }^{7}$ there have been no controlled studies comparing the 